\title{
DIFFERENCE OF COMPOSITION OPERATORS ON HARDY SPACE
}

\section{WALEed Al-RAWASHDEH AND Sivaram K. NARAYAN}

Abstract. Suppose $\varphi$ is an analytic self-map of open unit disk $\mathbb{D}$ and $w$ is an analytic function on $\mathbb{D}$. Then a weighted composition operator induced by $\varphi$ with weight $w$ is given by $\left(W_{w, \varphi} f\right)(z)=w(z) f(\varphi(z))$, for $z \in \mathbb{D}$ and $f$ analytic on $\mathbb{D}$. We find a sufficient condition under which two composition operators lie in the same path component of $\mathscr{C}\left(H^{2}\right)$, and we find a sufficient condition for the difference of such operators to be compact on $H^{2}(\mathbb{D})$. Then we provide another example that answers a question raised by Shapiro and Sundberg [18] negatively. Moreover, we characterize the Hilbert-Schmidt difference of two composition operators on $H^{2}(\mathbb{D})$.

Mathematics subject classification (2010): 47B38, 47B15, 47B33.

Keywords and phrases: Weighted Composition Operators, Compact operator, Hilbert-Schmidt operator, Carleson-type measure, pseudo-hyperbolic distance, Hardy space, Bergman spaces.

\section{REFERENCES}

[1] W. Al-Rawashdeh, Weighted Composition Operators on Weighted Hardy and Bergman Spaces, Ph.D. dissertation, Central Michigan University, 2010.

[2] E. BerkSON, Composition operators isolated in the uniform operator topology, Proc. Amer. Math. Soc. 81 (1981), 230-232.

[3] P. S. Bourdon, Components of linear-fractional composition operators, J. Math. Anal. Appl. 279 (2003), 228-245.

[4] P. S. Bourdon, D. Levi, S. Narayan, J. H. Shapiro, Which linear fractional composotion operators are essentially normal?, J. Math. Anal. Appl. 280 (2003), 30-53.

[5] T. Carroll And C. C. Cowen, Compact composition operators not in the Schatten classes, J. Operator Theory 26 (1991), 109-120.

[6] C. C. Cowen And B. D. MacCluer, Composition Operators on Spaces of Analytic Functions, CRC press, Boca Raton, 1995.

[7] P. DuREN AND R. WeIR, The pseudohyperbolic metric and Bergman spaces in the ball, Trans. Amer. Math. Soc. 359 (2007), 63-76.

[8] E. A. Gallardo-Gutiérrez, M. J. González, P. J. Nieminen, E. Saksman, On the connected component of compact composition operators on the Hardy space, Advances in Mathematics 219 (2008), 986-1001.

[9] P. Halmos, Measure Theory, Springer-Varlag, New York, 1950.

[10] J. E. LitTlewood, On inequalities in the theory of functions, Proc. London Math. Soc. 23 (1925), 481-519.

[11] B. D. MaCCluer, Compact composition operators on $H^{P}\left(\mathbb{B}_{n}\right)$, Mich. Math. J. 32 (1985), 237-248.

[12] B. D. MACCLUER, Components in the space of composition operators, Integral Equations and Operator Theory 12 (1989), 725-738.

[13] B. D. MacCluer AND J. H. Shapiro, Angular derivative and compact composition operators on Hardy and Bergman spaces, Canad. J. Math. 38 (1986), 878-906.

[14] J. Moorhouse, Compact difference of composition operators, J. Functional Analysis 219 (2005), $70-92$.

[15] J. Moorhouse And C. Toews, Difference of composition operators, Trends in Banach Spaces and Operator Theory (Memphis, 2001), Contemporary Mathematics 321 (2003), 207-213.

[16] W. Rudin, Function theory in the unit ball of $\mathbb{C}^{n}$, Springer-Verlag, New York, 1980. 
[17] J. ShaPIRO, Composition Operators and Classical Function Theory, Universitext: Tracts in Mathematics, Springer-Verlag, New York, 1993.

[18] J. H. SHAPIRO AND C. SUNDBERG, Isolation amongst the composition operators, Pacific J. Math. 145 (1990), 117-152.

[19] J. ShaPIRO AND P. D. TAYLOR, Compact, nuclear, and Hilbert-Schmidt composition operators on $H^{2}$, Indiana Univ. Math. J. 23 (1973), 471-496.

[20] K. ZHU, Operator Theory in Function Spaces, Monographs and Textbooks in Pure and Applied Mathematics, 139. Marcel Dekker, Inc., New York, 1990. 